\title{
Infant diarrhoea and subsequent mortality from heart disease and cancer
}

\author{
CAROL BUCK AND HELEN SIMPSON \\ From the Department of Epidemiology and Biostatistics, University of Western Ontario, London, Ontario
}

SUMMARY A preliminary examination of the relationship between the infant mortality of US birth cohorts and their mortality in later life suggested that infant mortality from diarrhoea and enteritis was particularly influential. In the 1917-21 birth cohorts of 17 US Registration States, infant mortality from diarrhoea and enteritis was significantly related to arteriosclerotic heart disease at ages 40-44 and 50-54 in both sexes, and to respiratory cancer at the same ages in men, after controlling for contemporary infant mortality. Hypotheses suggested by these relationships are put forward.

Since the early years of this century there have been sporadic investigations of the relationship between the early mortality of a birth cohort and its subsequent mortality in adulthood. The question is interesting because two opposite hypotheses have been advanced concerning the nature of the relationship. One predicts a negative correlation on the premise that mortality in infancy and childhood eliminates the weakest members of the cohort. The other predicts a positive relationship on the premise that infant diseases leave the survivor with an increased susceptibility to illness later in life.

Most of the early studies gave results that favoured the second hypothesis. ${ }^{1-3}$ More recently, Forsdahl examined Norwegian mortality data and found a positive relationship between infant mortality and subsequent mortality from all causes, arteriosclerotic heart disease, and cancer. The strongest positive relationship for cancer was that with lung cancer in men. ${ }^{4}$

The present report is based upon the analysis of birth cohorts in the Registration States of the USA. It introduces a new element by examining a specific cause of infant mortality in relation to the later mortality of the cohorts.

\section{Material and methods}

Mortality rates were obtained from regular publications of the US National Center for Health Statistics and from unpublished tabulations provided by the center. ${ }^{56}$

We began by examining correlations between infant mortality and adult mortality from various causes at ages 40-44 in two birth cohorts, 1917 and 1927. These analyses gave a surprising result, in that correlations for the 1917 cohort were significantly positive for arteriosclerotic heart disease and cancer, whereas all correlations for the 1927 cohort were close to zero. In an attempt to account for this difference, we examined the distribution of causes of infant mortality in the USA in 1917 and 1927. The outstanding difference was the much greater contribution of diarrhoea and enteritis to infant mortality in 1917 .

Accordingly we decided to study mortality from diarrhoea and enteritis in the cohort born in 1917-21, which reached ages 40-44 in 1961 and 50-54 in 1971. Mortality rates in 1917-21 for diarrhoea and enteritis were available for the individual Registration States at ages 0-2 years for the sexes combined.

Parametric correlations were used so that confounding variables could be controlled by multiple regression analysis. Since the dependent variable was reasonably normally distributed, this approach was considered to be appropriate.

Only 17 of the 20 Registration States were included in the final analysis because the number of adult deaths from specific causes was unacceptably small in Rhode Island, Vermont, and Utah.

\section{Results}

Table 1 gives the correlations between cohort infant mortality from infant diarrhoea and enteritis (IDE) and adult mortality from all causes, arteriosclerotic 
Table 1 Correlations* between mortality from diarrhoea and enteritis at ages 0-2 in 1917-21 and adult mortality in 1961 and 1971: US whites in 17 registration States

\begin{tabular}{llll}
\hline \multicolumn{4}{l}{ ADULT MORTALITY AT AGES 40-44 (1961) } \\
\cline { 2 - 4 } & All causes & Arteriosclerotic heart disease & Cancer \\
\hline Men & $+0.50^{* *}$ & $+0.55^{* *}$ & +0.36 \\
Women & +0.46 & $+0.68^{* *}$ & +0.09 \\
& ADULT MORTALITY AT AGES 50-54 (1971) & \\
\cline { 2 - 4 } & All causes & Arteriosclerotic heart disease & Cancer \\
\hline Men & $+0.70^{* *}$ & $+0.69^{* *}$ & $+0.55^{* *}$ \\
Women & +0.41 & $+0.62^{* *}$ & +0.13 \\
\hline
\end{tabular}

"Partial correlation, with contemporary infant mortality held constant.

$* *$ p $<0.05$ df $=14$

heart disease, and cancer. These are partial correlations, with contemporary infant mortality held constant. This precaution is necessary, for as Williams et al have shown, adult mortality tends to be correlated with both past and current rates of infant mortality. ${ }^{7}$

In both sexes, the correlations with heart disease were positive and statistically significant. The correlations with cancer were substantial only for men. Further analysis of cancer mortality revealed that among men the positive correlation with IDE disappeared when respiratory cancer was excluded but remained unaltered when gastrointestinal cancer, the other principal site, was excluded.

Table 2 gives the partial correlations of IDE with respiratory cancer for each sex. For men, but not

Table 2 Correlations* between mortality from diarrhoea and enteritis at ages 0-2 in 1917-21 and adult mortality from respiratory cancer in 1961 and 1971: US whites in 17 registration States

\begin{tabular}{llc}
\hline & \multicolumn{2}{c}{ Respiratory cancer mortality at ages: } \\
$40-44(1961)$ & $50-54(1971)$ \\
\hline Men & $+0.50^{* *}$ & $+0.63^{* *}$ \\
Women & -0.14 & +0.21 \\
\hline "Partial correlation, with contemporary infant mortality held constant. \\
" p $<0.05$ df = 14
\end{tabular}

women, the correlations were significant, and larger than those between IDE and total cancer mortality.

Before proceeding further, we made a rough check on the plausibility of these results by computing the correlation between cohort IDE and mortality from accidents, at ages 50-54. There is virtually no biological basis for expecting a positive association and, should one be found, the other results would best be attributed to the pitfalls of ecological correlation. In men, the partial correlation coefficient between IDE and accident mortality was +0.09 and in women $+0 \cdot 18$. This encouraged us to continue.

The next step was to consider how, in the absence of any aetiological connection, mortality from infant diarrhoea might be statistically associated with adult mortality from heart disease and respiratory cancer. It is not difficult to think of a mechanism for a spurious correlation between infant diarrhoea and respiratory cancer. States that are now highly industrialised and offer abundant occupational exposure of men to respiratory carcinogens might, in the earlier years of the century, have provided an environment conducive to outbreaks of infant diarrhoea. If cigarette smoking among men were more prevalent in such States, a non-causal association of IDE would be expected with male adult mortality from heart disease as well as from respiratory cancer. If either of these explanations were correct, the correlations with IDE should be equally high among States in which a substantial proportion of the adult men had been born elsewhere. This was tested by recomputing the correlations with IDE after grouping the 17 States according to the proportion of adult men born in the State of residence. Data from the 1960 US census were used for this purpose. The results, given in Table 3, show that the zero-order correlation coefficients and slopes were larger among States in which at least $70 \%$ of men aged $40-44$ were born in the State of residence. Although this observation is far from conclusive, given the small number of States in each group, it does not support a non-aetiological explanation of the associations between IDE and adult mortality.

A non-aetiological explanation was further tested by a multiple regression analysis in which IDE, cigarette consumption, ${ }^{8}$ an index of industrialisation, ${ }^{9}$ and contemporary infant mortality were the independent variables. Only 16 States could be used in the regression analysis because data on the

Table 3 Correlation analysis of mortality from diarrhoea and enteritis at ages 0-2 (1917-21) and mortality at ages 40-44 (1961) among white men in two groups of States

\begin{tabular}{|c|c|c|c|c|c|}
\hline & \multirow[b]{2}{*}{$\%$ men $40-44$ born in State (1960 Census) } & \multicolumn{2}{|c|}{ Arteriosclerotic heart disease } & \multirow{2}{*}{$\frac{\text { Respiratory cancer }}{\text { Zero-order } r}$} & \multirow[b]{2}{*}{ Beta } \\
\hline & & Zero-order $\boldsymbol{r}$ & Beta & & \\
\hline $\begin{array}{l}\text { Group } A^{*} \\
\text { Group } B^{* *}\end{array}$ & $\begin{array}{l}70 \% \text { or more (average } 78 \% \text { ) } \\
\text { Under } 70 \% \text { (average } 56 \% \text { ) }\end{array}$ & $\begin{array}{l}+0.58 \\
-0.34\end{array}$ & $\begin{array}{l}+0.007 \\
-0.001\end{array}$ & $\begin{array}{l}+0.75 \\
+0.34\end{array}$ & $\begin{array}{l}+0.002 \\
+0.001\end{array}$ \\
\hline
\end{tabular}

*Maine, Massachusetts, Minnesota, New York, Pennsylvania, Kentucky, North Carolina, and Wisconsin.

* Connecticut, Maryland, Michigan, New Hampshire, Indiana, Kansas, Ohio, Virginia, and Washington. 
independent variables were incomplete for one State. Table 4 shows that for men and women the partial regression coefficients for IDE on arteriosclerotic heart disease were positive and statistically significant, whereas those for respiratory cancer were significant only for men.

Table 4 Standardised partial regression coefficients for diarrhoea and enteritis mortality at ages 0-2, 1917-21, in a multiple regression analysis* of adult mortality of the birth cohort: US whites in 16 registration States

\begin{tabular}{lll}
\hline & \multicolumn{2}{c}{ Mortality at ages: } \\
& $40-44$ & $50-54$ \\
& $(1961)$ & $(1971)$ \\
\hline MEN & & \\
Arteriosclerotic heart disease & $+0.62(p=0.03)$ & $+0.80(p=0.01)$ \\
Respiratory cancer & $+0.61(p=0.03)$ & $+0.68(p=0.03)$ \\
WOMEN & & \\
Arteriosclerotic heart disease & $+0.49(p=0.02)$ & $+0.63(p=0.04)$ \\
Respiratory cancer & $+0.02(p=0.94)$ & $+0.31(p=0.27)$ \\
\hline
\end{tabular}

*The other independent variables are:

(1) Contemporary infant mortality $(1961,1971)$

(2) Per caput sale of cigarettes, 1950

(3) Per cent of population aged 20-64 employed in manufacturing, 1957

\section{Discussion}

On the reasonable assumption that the infant mortality rates reflect the prevalence of severe forms of diarrhoea, our results suggest that attacks of such infections are associated with an increased risk of death from heart disease in both sexes and respiratory cancer in men in later life.

What might be the biological basis for these associations?

Let us begin with the association of infant diarrhoea with respiratory cancer. The restriction of the association to men makes it unlikely that an enteric infection could have any directly carcinogenic effect. However, in the birth cohort that we have studied, men would have been much more intensely exposed than women to tobacco and to industrial carcinogens. This suggests a possible connection between infantile enteric infection and the response to respiratory carcinogens later in life. Such a connection could be postulated in terms of vitamin A metabolism, given the evidence that vitamin A inhibits the squamous metaplasia of respiratory epithelium after exposure to carcinogenic hydrocarbons. ${ }^{10}$ Nalin and Russell have found a marked suppression of vitamin A absorption after acute watery diarrhoea. ${ }^{11}$ Nalin suggests that multiple attacks of diarrhoea could lead to chronic vitamin A deficiency as a result of persistent bowel infection by organisms both utilising vitamin $\mathrm{A}$ and interfering with its absorption (Nalin DR, personal communication, 1981). How prolonged such an effect could be is not known.

We turn now to the association of infant diarrhoea with arteriosclerotic heart disease. Two possible explanations can be advanced.

The first derives from Mathews's theory that infection facilitates the production of autoimmune complexes which promote the later development of arteriosclerotic lesions. Mathews and his colleagues suggest that the recent decline in mortality from hypertensive vascular disease could be a late result of the decreased burden of infection in childhood. ${ }^{12}$ In considering this possibility one has to make the assumption that enteritis is more likely than other childhood infections to invoke an autoimmune response.

The second possibility is that breast-feeding is the common denominator, protecting the infant against diarrhoea ${ }^{1314}$ on the one hand and, on the other, inducing enzymes that promote efficient metabolism of cholesterol not only in infancy but throughout adult life. ${ }^{15}$ If this were the case, the association between infant diarrhoea and heart disease would be a non-causal one. This explanation is weakened by recent data from the National Birth Survey in England which showed that only in women was the adult level of plasma cholesterol lower among those who had been breast-fed in infancy. ${ }^{16}$

This discussion is highly speculative and perhaps more extensive than is warranted from ecological correlations. Nevertheless, ecological correlations can be useful in suggesting hypotheses for further study. The observations we have reported should encourage further investigation, particularly of the long-term consequences of infant diarrhoea, a disease that is still very prevalent in many parts of the world.

We thank Joan B. Keemer of the Mortality Statistics Branch, National Center for Health Statistics, who supplied much of the data necessary for the cohort mortality and analyses, and Dr. Allan Donner for his advice on the statistical analyses.

Reprints from Dr. Carol Buck, Department of Epidemiology and Biostatistics, University of Western Ontario, Kresge Building, London, Ontario, Canada N6A 5B7. 


\section{References}

${ }^{1}$ Kermack WO, McKendrick AG, McKinley PL. Death-rates in Great Britain and Sweden. Some general regularities and their significance. Lancet 1934; i: 698-703.

${ }^{2}$ Jones HB. A special consideration of the ageing process, disease and life expectancy. Adv Biol Med Phys 1956; 4: 281-337.

${ }^{3}$ Legare J. Quelques considérations sur les tables de mortalité de generations. Population 1966; 21: 915-31.

${ }^{4}$ Forsdahl A. Are poor living conditions in childhood and adolescence an important risk factor for arteriosclerotic heart disease? Br J Prev Soc Med 1977; 31: 91-5.

${ }^{5}$ Department of Commerce, US Bureau of the Census. Mortality Statistics 1921 (published and unpublished data). Washington DC: US Bureau of the Census, 1924.

${ }^{6}$ US Department of Health, Education and Welfare. Vital Statistics of the United States, vol..II, part B. Washington DC: USDHEW, 1961 and 1971.

${ }^{7}$ Williams DRR, Roberts SJ, Davies TW. Deaths from ischaemic heart disease and infant mortality in England and Wales. J. Epidemiol Community Health 1979; 33: 199-202.

${ }^{8}$ Tobacco Tax Council. The tax burden on tobacco, vol. III. Richmond, Virginia: Tobacco Tax Council, 1968.
${ }^{9}$ Department of Commerce, US Bureau of the Census. Annual Survey of Manufacturers. Washington DC: US Bureau of the Census, 1957.

${ }^{10}$ Saffrotte V. Metabolic host factors in carcinogenesis. In: Doll R, Vodopija I, eds. Host-environment interactions in the aetiology of cancer in man. IARC Scientific Publication No. 7. Lyons: IARC, 1973.

${ }^{11}$ Nalin DR, Russell R. Vitamin A, xerophthalmia and diarrhoea. Lancet 1980; i: 1411.

${ }^{12}$ Mathews JD, Whittingham S, Mackay IR. Autoimmune mechanisms in human vascular diseases. Lancet 1974; ii: 1423-7.

${ }^{13}$ Ironside AG, Tuxford AF, Heyworth B. A survey of infantile gastroenteritis. $\mathrm{Br} \mathrm{Med} J$ 1970; iii: 20-4.

${ }^{14}$ Stoliar OA, Kaniecki-Green E, Pelley RP. Secretory IGA against enterotoxins in breastmilk. Lancet 1976; i: 1258-61.

${ }^{15}$ Nutrition Committee of the Canadian Paediatric Society and the Committee on Nutrition of the American Academy of Pediatrics. Breast-feeding. Pediatrics 1978; 62: $591-601$.

${ }^{16}$ Marmot MG, Page CM, Atkins E, Douglas JWB. Effect of breast-feeding on plasma cholesterol and weight in young adults. J Epidemiol Community Health 1980; 34: 164-71. 